\title{
Sustainable Leadership Supporting Educational Transformation
}

Katherine Sanford, Timothy Hopper, Kerry Robertson, and Dana Bell

\author{
University of Victoria \\ Vivian Collyer \\ Laura Lancaster \\ Sooke School District
}

British Columbia Ministry of Education

\begin{abstract}
The world, influenced by 21 st century technologies and ecological challenges, has rapidly changed with more ability to "connect" locally and globally and more opportunities to learn from a range of sources. As a result, our learners and their needs have changed. With such rapid changes, conceptions of educational leadership need to reflect these changes utilizing the complexities of the role in society. As a group of educators who work in a School District, Ministry of Education and University teacher education programs, we ask how educational leaders in school districts and teacher education programs can design spaces that engage everyone, recognize everyone's expertise and share responsibility for growth and development, and how in teacher education we can begin to move away from the hierarchical, industrialized model of management to one where everyone feels engaged, valued, and heard. In this paper, we draw on sustainable and distributed leadership ideas, termed by Wheatley (2010) as the "new sciences," informed by tenets from complexity theory. Using a case study approach and narrative insights, this paper elucidates how an ongoing Professional Learning Network (PLN) called Link-toPractice (L2P) offers an alternative conception of educational leadership.
\end{abstract}

Keywords: case study; narrative, qualitative research, complexity theory
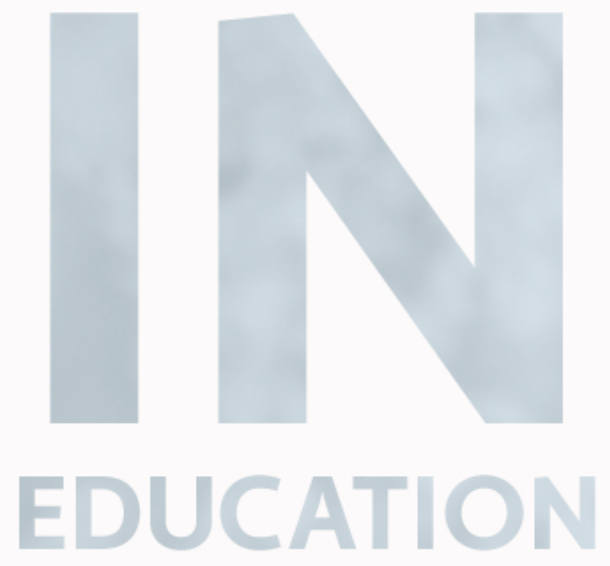


\section{Sustainable Leadership Supporting Educational Transformation}

Another staff meeting, another two hours of listening to my principal reading out announcements, new directives from central administration, and a "discussion" about our next professional development day (the theme of "safe use of technology" had already been selected). The principal and vice principal sat at the front of the room, able to survey the actions of the staff, who were busy with their coffee and donuts, shifting a bit in our seats, unable to bring any teacher work into the meeting because of a previous administrative decision. I couldn't help thinking about the meaningful tasks I still had to do, but that needed to wait until the end of the meeting. I couldn't help wishing we had some input into the structure or the agenda for the meeting, knowing that this suggestion wouldn't be received well by the admin team Mr. Brown and Mr. Anderson.

This opening anecdote captures a recurring pattern of leadership meetings in our educational institutions across decades. This paper considers how leadership could be conceptualized and developed differently. The world has been rapidly changing with new technologies, access to information, family structures, diversity and mobility, and awareness of ecological challenges, to name a few. As a result, learners and their needs have changed. They have more immediate access to information, more ability to "connect" locally and globally, and more opportunities to learn from a range of sources. However, leadership roles often remain static, hierarchical, and linear, stuck in an industrialized model of management. As noted by leadership scholar Fairholm (2004), we are caught in a Newtonian metaphor of mechanistic predictability, and, "the world of organizations has come to recognize the limitations of traditional management theories to describe fully the 'hows' and 'whats' of operating in a collective environment" (p. 370). With such rapid changes, conceptions of leadership and strategies used by educational leaders need to reflect the changes surrounding them, utilizing the complexities of educational institutions rather than ignoring them. One strategy that has emerged to address these concerns in education is the development of professional learning networks (PLN). Informed by Wenger's (1998) theory of communities of practice and drawing on Brown and Poortman (2018), we define PLNs as collectives of like-minded professionals who engage in collaborative learning with "others outside of their everyday community of practice in order to improve teaching and learning in school(s) and/or the school system more widely" (p. 1).

As educators who work across large organizational structures, including the Ministry of Education, university teacher education programs and school districts, we have formed a PLN to address our common concerns about the lack of informed leadership in the professional development of teachers and the disconnect between preservice and in-service teacher education. We ask two shaping questions for this paper: How can educational leaders in school districts and teacher education programs design spaces that engage everyone, recognize everyone's expertise, and share responsibility for growth and development and how in teacher education can we begin to move away from the hierarchical, industrialized model of management to one where everyone feels engaged, valued, and heard?

Drawing on sustainable, distributed and "new science" (Wheatley, 2010; 2017) comprising ideas found in quantum physics, autopoietic theories found in biology, chaos theory, and complexity science) leadership ideas, this paper will offer insights on how an ongoing PLN called Link-to-Practice (L2P) has been developed over the last four years from a partnership 
across school, district and university based teacher education programs. In this paper we share our perceptions as project leaders, through a case study approach that draws on narratives and personal reflections, to examine our conceptions of sustainable leadership that has supported our PLN and our ongoing educational transformation work for preservice and in-service teachers. We explain the characteristics of sustainable leadership utilizing a feminist framework to inform the concept of "sustainable leadership" that is distributed across institutions and draw on complexity theory to describe and interpret examples of sustainable leadership through the L2P project. Similar to Hargreaves and Fink's (2004) use of complexity theories, we frame sustainable leadership as an emerging model that moves away from a technical managerial model to one of relational networking, ground up decision making and shared ownership.

\section{Leadership and Link-to-Practice}

For the past 10 years, BC's educational system has engaged in transformation of curriculum, assessment, and beliefs and assumptions about learning. This significant undertaking has impacted the work of teachers, students, and parents, and educational staff (Fu, Hopper, \& Sanford, 2018). As educators in diverse educational sectors, we question whether the typical hierarchical educational leadership has adapted to the changes of learners, teachers, and institutions. The hierarchical managerial model, in which there is a reporting up to the boss, who in turn has a boss, is not a model that supports today's world (Sergiovanni, 2007). In this linear managerial model, the individual with the most power is the one most removed from understanding the complex contexts in which daily work happens. The complexities of today's fast-paced, information-burgeoning world, where change is the norm, requires a leadership model where expertise is shared by everyone in the community. No longer can one individual have all knowledge, understanding, and skills in which to make effective timely decisions. New skills are needed - skills involving praxis and dimensions of leadership, and abilities to act based on informed reflection (Furman, 2012). The shared anecdotal experience below from three of the authors offers an example of typical institutional leadership.

We held a full-day workshop last year to discuss our teacher education program, analyze what is working, what is not meeting the needs of our teacher candidates, and models for change. The room buzzed with ideas, camaraderie, and possibility. Models were sketched out on chart paper, connections between individuals were made, excitement and future development enriched the conversations. Since that lively daylong meeting, however, no further action has been taken - there has been little action or engagement. We are not sure how others feel six months later, but we are disappointed and left wondering about the purpose of the meeting.

This anecdote captures a space where the hope of decision-making informed by ground-up, interconnected and collective commitment was implied but then lost, with no conditions available to move the forming collective system forward. Furman's (2012) conceptual framework for leadership, grounded in a review of social justice leadership literature, speaks to the conditions that were lacking in this experience, suggesting three central concepts for organizing distributed socially just leadership. First, leadership for equity and shared responsibility is conceived as a praxis, in the Freireian sense, involving both reflection and action. Second, leadership for social justice spans several dimensions, which serve as arenas for this praxis. These dimensions include the personal, interpersonal, communal, systemic, and ecological. Third, each dimension within the framework requires the development of capacities on the part of the leader and those involved, 
capacities for both reflection and action. Leaders in today's educational systems need to develop these capacities as they support their colleagues, peers, and most importantly, their learners. And while the retreat described above attempted to create excitement and community, the leadership was not grounded in sustainability of the shared leadership intent or the potential for reflexivity from ongoing connectivity. It was simply a scheduled event; the infrastructure or planned commitments to respond to the meeting were not available.

\section{Content of the Link-to-Practice Study: Sustainable Leadership emerging from a PLN}

We believe that the Link-to-Practice (L2P) project tells a different story. Individuals with minor leadership responsibilities within aspects of their system came together from across different educational institutions. Together they formed a PLN made up of two district curriculum leaders and three teacher educators (field experience co-ordinates and program lead) from the local university. Their goal was to develop a model of sustainable professional learning for teacher candidates, new career teachers, and experienced teachers - all at the same time. The L2P project built on an existing school-integrated secondary teacher education partnership that had been running since 2012 (Hopper, 2015; Sanford, Hopper, \& Starr, 2015). The organizing principles of the L2P program, developed collaboratively within the PLN, were three-fold: (a) to enable new teacher candidates to experience school life early in their program; (b) to integrate teachers and administrators in meaningful ways into teacher education; and (c) to provide a context for campusbased teaching relating to the reality of today's schools. What developed in addition to these objectives were meaningful professional learning opportunities for the leaders in the PLN, teachers involved in L2P, both new career teachers and senior members of the profession, as well as the teacher candidates. The L2P project evolved for the particular needs of the school district in light of new curriculum redesign, the teacher education program and the teacher education candidates. Recognizing the small size of most elementary schools in the district, the team sought not one school for each seminar and field experience as in the existing secondary education model (Sanford et al., 2015), but rather a cluster of elementary and middle schools to host teacher candidates each Wednesday for the entire term. At the end of the day seminar instructors, who were also educators in the school district, met with teacher candidates who had spent the day in the school working with their partner teachers who had all volunteered to host a pair of teacher candidates. Additionally, all of these partnering educators were released by the school district from their schools to attend the three-day-long professional learning workshops/meetings held throughout the year, along with their teacher candidates; these professional learning workshops were co-created by the PLN members, led by the district partners, and supported by the university teacher educators. In all of the situations described there was ongoing interactions that led to shared leadership, plans, action and reflections; at times sessions were led by school-based teachers, district personal or university instructors. Over time teacher candidates took up leadership roles as they reported on experience or shared important life experiences related to issues being addressed.

\section{Theoretical Framework for Sustainable Leadership in a Complex World}

Leadership is in crisis. "We need braver leaders and more courageous cultures," suggests Brown (2018, p. 6) and educators need to consider leadership - for themselves and others - early in their careers. Those in leadership power positions are still operating in a hierarchical system where those at the "top" make arbitrary decisions that filter down to the "lower" levels of an educational organization - without consultation or seeking to understand the complexities of the organization. 
Rather than individual decision-making, we need to better respond to the frenetic nature of today's work world, and to create time and space/place to share, connect, and listen to multiple perspectives with respect and consideration. We also need to take time to better understand the systems in which we are working so that reflection and action is informed and considered rather than "off-the-cuff" and inconsistent. In Greene's (1995) terms, we need to be able to see the world big (close up in all its particularities) and small (stepping back to understand the larger context) and also to make connections between the two. In addition to being reflective and considered, leadership needs to be consistent, fluid, and responsive to both the educational vision of the system and to the local needs of individuals in unique contexts. We need to see leadership move from top-down management to responsive, emergent, and connected networks.

Many educational leaders are products of dated structures and systems and struggle to sustain either their positions or their systems; today's educational systems require different characteristics in order to sustain their organizations. As noted by several scholars (Fullan, 2005; Uhl-Bien, Marion, \& McKelvey, 2007; Wheatley, 2017), leaders, rather than being individualistic and self-sustaining, need to use analytical and ethical thinking, reorienting their understanding about the nature of leadership. As noted by Brown (2018) and Wheatley (2017), we need leaders who, as part of a distributed model, demonstrate collegiality and democratic processes, determining priorities collectively for the needs of their communities and their mutual benefit.

\section{Complexity Theory Tenets and Collective Human Behaviour}

To understand our perspective on leadership we draw on complexity theory (Capra \& Luigi Luisi, 2014; Davis, Sumara, \& Luce-Kapler, 2015) and the insights of the new sciences suggested by Wheatley $(2010,2017)$ and Fairholm (2004). Complexity theorists offer a way of studying complex phenomena through the description of how order can emerge in collective human behaviour that self-organizes around certain attractors or commitments. Complexity theory scholars note that, as in the physical sciences, humans are made up of and work within complex self-organizing systems. As noted by Waldrop (1992), complexity theory has been used to describe the organizational structures that emerge in both nature and social spaces that is implicit within Wheatley's (2010) analysis of how the new sciences can inform leadership and institutional organizations. Researchers use complexity theory in order to understand how order and stability arise from the chaotic interactions of many components as they start to function according to a few simple rules (Mason, 2008). As Mason (2008) noted, complexity theory and chaos theory share a focus on "sensitivity of phenomena to initial conditions" (p. 6) for its structural organization to emerge. Based on adherence to simple rules and optimum conditions (enabling constraints), complex systems allow the social agents of a system, through continuous feedback loops and neighbourly interactions, to adapt into self-sustaining collectives that behave often in unpredictable but coherent ways (Cilliers, 2000; Mason, 2008).

In this paper, we consider how leadership in our local educational systems has developed characteristics of a complex learning system as we learn to pay attention to key tenets from the new sciences (Wheatley, 2010). As noted by Wheatley and Frieze (2015), in contrast to reductionist sciences based on Newtonian principles focused on parts and measurements, the new sciences focus on holism, the whole system, with attention given to relationships between people, often referred to as agents in complexity theory, within networks and what emerges. We have clustered key tenets of complexity theory into areas that we feel need to be present for new science sustainable leadership where agents of a system form a complex system connected to a common 
goal around institutional projects: (a) attractors or common interests within supportive contextual affordances that feed the passions of those involved and help develop a collective memory; (b) adaptive emergence through decentralized control in relation to ambiguously bounded structures that enable change while maintaining coherence; and (c) interconnections between diverse agents through neighbourly interactions, redundancy between parts of the systems so that the system can compensate for any loss, and recursive elaboration of skills and knowledge for agents as the systems engages with the environmental challenges.

Sustainable leadership as distributed and feminist. Considering the idea of attractors, and drawing on distributed leadership (Bennett, Wise, Woods, \& Harvey, 2003) and transformative feminist leadership (Wakefield, 2017), we believe that leadership should demonstrate shared vision (a common passion) that is empowering and enables others to act, challenging oppressive norms and power and encouraging integration of heart, mind, and body. As noted by Clover, Etmanski, and Reimer (2018), "Feminist leadership discourse positions leadership as a means, not an end" (p. 26). Through this understanding, then, it is more important to consider the nature of change that leadership seeks to bring (Batliwala, 2013) rather than describing leadership. "Central to feminist leadership is a commitment to working as allies and change agents across movements, communities, and institutions to create a broader base of equity among otherwise marginalized, ostracized, or oppressed peoples" (Batliwala, 2013, p. 27). Further, Batliwala (2013) suggests that "feminist leadership must begin at home, from within the organization, movement or any other location from which women are attempting to change the larger reality... to create alternate models of power within their own structure" (p. 190). Wakefield (2017) notes that feminist leaders come to understand the needs of their communities and prioritize those needs, engaging them fully for mutual benefit. Distributed leadership aligns with Wakefield's feminist leadership notions; as Bennett et al. (2003) describe, there are three distinctive elements of distributed leadership:

- leadership is highlighted as an adaptive emergent property of a group or network of interacting individuals, where people work together and pool their initiative and expertise;

- there is an openness of the boundaries of leadership suggested, widening the conventional net of leaders to include teachers and students; and

- expertise is varied and distributed across the many, not the few and that numerous distinct germane perspectives and capabilities are found in individuals spread through the organization (p. 6-7).

All these principles align well with the complexity theory tenets emphasized in the previous section. In the next section we outline how we have researched sustainable leadership in the L2P model through a case study approach and story analysis.

\section{Case Study and Narrative Insights}

This study draws on what Stake (2005) calls an intrinsic case study approach focused on how the L2P leadership PLN emerged. To understand the L2P model we present shared narratives, critical events, and artifacts such as meeting notes to frame the analysis on how the L2P project evolved. Focused on leadership we have created a reflective case study to explore how the sustainable and distributed feminist leadership approach emerged within the project. Three of the authors worked within the university and two in the school district with the sixth author operating as a critical friend, offering a reflective perspective from outside of the project in a collaborative 
process (Placier, Pinnegar, Hamilton, \& Guilfoyle, 2005). Narrative analysis, as an umbrella term, is a method that takes the story, in this case the development of the L2P approach, and makes it the object of enquiry in relation to the research question (Smith \& Sparkes, 2009). Riessman (2008) notes that narratives depend on certain structures such as plot, characters, and outcomes to hold them together. A common assumption is that our lives are stories and that the self is narratively constructed. As noted by Sparkes and Smith (2014), through telling stories "people give meaning to their experiences within the flow and continuously changing contexts of life" ( $p$. 46). These stories claim a form of truth, not universal, but rather one that rings true to the reader, offers elements of a culture that are recognizable, and shows how the events in the story allow these elements to interact in novel ways to generate new realities, believable possibilities. This idea has been termed a form of verisimilitude within qualitative research approaches (Creswell \& Miller, 2000; Sparkes \& Smith, 2014). We respond to the two research questions through an analysis of the L2P story through reflections that are shared, linking these accounts from the authors to the theoretical framework that is informed by complexity thinking and feminist distributed leadership. Our research questions, then, focus, first, on how educational leaders in school districts and teacher education programs design spaces that engage everyone, recognize everyone's expertise, and share responsibility for growth and development and, second, on how in teacher education, we can begin to move away from a hierarchical, industrialized model of management to one where everyone feels engaged, valued, and heard.

Data collection and analysis. To track the development of the L2P project, the research team gathered data over the last three years from meetings between the participants. Both school and campus partners created documents (PowerPoint presentations, agendas, descriptions of the program). These artifacts then served to inform the following analysis and outline of the development of the L2P model. Additionally, extensive notes from multiple sources were taken, analyzed and shared across the group, enabling ongoing and meaningful individual and collective reflection. Detailed and extensive notes were taken at: (a) the four annual professional learning sessions (attended by seminar instructors, partnering educators, teacher candidates and the leadership partners); (b) planning and debrief meeting notes (two times each year); and (c) personal observations from the authors gathered at the end of each year. All these data sources were gathered together and reviewed by the team for common patterns and recurring processes. The analysis process was done by hand but also cross-referenced through group discussions and reflections on the ideas implicit in the organizing tenets from complexity thinking.

\section{The Initial Conditions: Two Initiatives Coming Together}

Post-degree teacher education program. At the University the 16-month Post Degree Professional (PDP) teacher education program enrolls a cohort of 25 to 30 teacher candidates each year who have previously completed a Bachelor of Arts or Science degree. While the group is fairly homogenous in regard to race and cultural background, their ages, gender, and experiences are varied. The L2P project is focused on the first term of the program, although there is space in teacher candidates' schedules in subsequent terms to continue their professional connections and relationships if they choose. In addition to the L2P school connections and seminar on Wednesdays (described below), the teacher candidates also take five other courses during their first term, including curriculum and pedagogy, indigenous education, assessment, child development and literacy. Their program consists of two subsequent formal practicum experiences, a 6-week spring practicum at the conclusion of their first two terms, and a 9-week practicum the following fall. 
School District. The L2P integrated TEP was a natural extension of work that had been going on in the school district for a number of years. The culture of feminist distributed leadership in the school district for ongoing professional learning was prevalent, valuing teacher expertise in collaborative learning. Interestingly, this process of distributed leadership was noted by Campbell (2017) in a Canada-wide study as a common intent of school districts. However, Campbell noted that this approach often resulted in tensions between well-meaning leaders and teachers who felt pressured into complying with a new initiative. In this case, however, the district leadership team had facilitated teacher inquiry and mentorship in school teams in systematic and informed ways since 2004, including opportunities for teachers to investigate and share their practices in supported and collaborative ways. Prior to the L2P partnership, the culture of professional learning in the school district was framed around positive respectful relationships and community efficacy in safe and encouraging spaces. From 2012-2015, prior to the inception of the L2P program, the district team had provided formalized mentor training in peer-coaching conversations and support for new career teachers' professional growth interests.

In the fall of 2015, district staff from School District heard about the secondary education model of integrated teacher education from their informal school district networks, and met with teacher educators at the University to propose a partnership with their district for elementary education. Their vision was to combine their successful peer-mentoring model with practicing teachers with the secondary school integrated teacher education within local elementary schools from the beginning of their Elementary Post Degree Program (PDP) - beginning the following year. From this initial meeting the L2P project leadership team was born, creating the informal PLN comprised of the five educators. The L2P team came together not from a directive from the district superintendent or from the Faculty of Education administration; rather the team came together through mutual desire to enhance what was already working well but could become better. All five members of the L2P team saw the need for restructuring roles and building a new relationship between the TEP and school district as they moved forward to support their teachers and teacher candidates. From this foundation the collaborative and distributed leadership PLN model emerged.

The relationships that were developed in the district through the L2P project enabled the district leaders to see their teachers operate in different ways in a mentoring role, enabling them to encourage and invite other teachers they thought would be interested into the TEP community to share their ideas and practices. This district environment, then, provided a supportive space to include teacher candidates along with teachers, creating (in complexity thinking terms) the initial conditions.

\section{Setting Up and Interconnecting}

After several early meetings and discussions, the partnership L2P was piloted in September 2016 and now, after regular ongoing meetings with the PLN group, is in its fourth iteration. The school district identified seven elementary and middle schools in close proximity to each other and invited teachers to volunteer to mentor a pair of university teacher candidates for the Elementary PDP program, including the teacher candidates in their classes each Wednesday for the fall term. These partnering educators committed their time and expertise, "welcome[ing] teacher candidates into their daily teaching and learning experiences, pedagogical conversations, and professional communities" (Collyer, 2016, L2P Flyer). During each of the Wednesdays throughout the term (approximately 11 day-long visits between September and December), the 
partnering educators, drawing on their professional learning model in the school district, committed to modeling effective teacher practices, engaging in peer-coaching conversations, providing opportunities for teacher candidates to work with groups of students in educative ways, offer feedback to teacher candidates, and attend two district-sponsored professional learning workshop afternoons.

To further connect the university and school district, one of the courses in the Elementary PDP program, the Field Experience Seminar, was taught each Wednesday after school at one of the participating school sites by two district educators, identified and hired by the University as course instructors. This seminar was designed to guide the experiences on Wednesdays by providing focus questions, text prompts or readings prior to the Wednesday visits, followed by a debrief and extension of learning after school. Topics included exploration of new curriculum, alternative assessment practices, relationship building, effective management strategies, integrating First Peoples' Principles (n.d.), and support of all learners, to give just a few examples. The expectation of the teacher candidates was to immerse themselves in the life of the school on Wednesdays and to actively observe and participate in their partnering educators' classes. The after-school seminar was intended as an opportunity for them to share their experiences with their peers and seminar leaders and begin to connect theories and practices across their coursework. For many, it was the first time they had been in elementary and middle schools since they were students there themselves. During the second and third years of the L2P project, the district invited secondary seminar instructors and teacher candidates to join the professional learning workshops, increasing the dynamic nature of the discussions, topics, and perspectives.

The professional learning afternoons, attended by over 50 teacher candidates, 20 partner educators, and the L2P PLN leadership team, were designed to explore teacher inquiry. The teacher candidates also themselves engaged in an inquiry during the fall term, supported at the University and school site, thus participating in professional learning right from the beginning of their program. Through these professional learning afternoons, partnering educators had opportunities to share their inquiry journeys, guide the teacher candidates, reflect on their experiences, describe how inquiry shaped their professional practice, and open new avenues for investigation. These non-evaluative opportunities offered a new model of professional learning for the participating teachers, allowing them the time to share with one another, the teacher candidates and with their administrators/leaders. As their role was one of supportive mentor, they were not required to evaluate or judge the teacher candidates' skills or attitudes, but rather to provide ongoing guidance creating ongoing formative feedback loops in relation to dynamic situations that teacher candidates had chosen to engage in. From the teams' observations it was clear how the teacher candidates were enthusiastic and energized in the professional learning sessions as they grappled with inquiry questions, sought out feedback from their peers and partnering educators, and reflected on their own learning.

As the PLN team reviewed the data from their three years, several significant themes emerged for them. The feminist distributed leadership approach encouraged empathy to develop among the PLN team as well as for the L2P educators; the empathetic relationship enabled the team to seek further opportunities, take risks, and create new experiences that responded to the needs of the educators and to challenging existing structures and rules that did not support learning. For example, there was a shifting the timetable of meetings to accommodate all of the five educators' schedules so they were able to meet with each other and the teachers to share insights across their institutions. Throughout the project the team learned to adopt new roles and 
adapt previous ones, sharing roles of teacher educator, guide, administrator, and mentor. For example, teachers became teacher educators speaking about the teacher education program as something they now worked in, rather than finding fault with a program with which they had no connection. Ongoing reflection and sharing enabled stories about the L2P to emerge, and the team recognized the importance of telling good stories. These included, for example, teacher candidates' revelations about new practices they saw in the schools that connected to ideas studied at the university, or a teacher sharing insights on how well an Indigenous student had led the land acknowledgement in a way he never could have done. These types of emerging stories sustained and developed the project.

\section{Empathy}

Empathy is connecting to the emotions that underpin an experience. (Brown, 2018, p. 118)

One of the significant aspects of this L2P project and partnership was the ability of the L2P PLN leadership team to relate first to each other and then to the teachers and teacher candidates they were supporting. As noted by one of the school-based PLN members,

The closing line of one of the earliest email exchanges between the five of us reads:

"We are very excited about this project and are very encouraged by the positive responses from our teachers about the idea so far! Thank you so much for partnering with us!" (Collyer, April 5, 2016). It was a novel experience to have districts so actively engaged in creating spaces for our teacher candidates beyond the formal practicum experiences.

Viewing the world through an empathetic lens raises awareness of the differences that make teachers and students unique and prompts questioning the way in which students and teachers are experiencing their education (Gallagher \& Thordarson, 2018). Recognizing individual needs in relation to system needs inspired this PLN leadership team to seek ways to engage in conversations with each other that led to recognizing and then understanding alternative perspectives. Sharing insider perspectives, both from a district perspective and the campus perspective, created spaces for outsider feedback, strengthening both the relationships and the potential project. This then led to exploration of further opportunities and deepening insights into the partnership as members of the team found an intuitive sense of connection. Wheatley (2010) refers to intuitive connections to the invisible fields of connection in quantum physics as relational holism where "it is no longer meaningful to talk of the constituent electrons' individual properties, as these continually change to meet the requirements of the whole" (Chapter 6, para 53). Through careful listening and observing in meetings, workshops, and informal conversations, the team developed trust and respect for each other; they were then able to transfer those empathetic perspectives to the teachers and teacher candidates, the self-similarity of walking the talk transferred to the teacher candidates. Further, the leadership team encouraged empathy in those participating in the L2P project and through structured and informal connections came to understand each other's realities and views.

For example, once the project was conceptualized, a first meeting with the district leaders, teacher education leaders, and potential teacher partners was held where the possibility of participating was suggested. This was an opportunity for teachers to ask questions, make 
suggestions, and consider their involvement. The reflection from one of the university team members below captures this empathy forming connection.

Sitting around a large table, after a lunch provided by the district team, teachers were guided through some brief activities to stimulate their thinking, followed by a description of the potential project. Teachers at the table looked engaged and thoughtful as they explored their own views and considered the possibilities of presenting to the teacher candidates. This was the beginning of ongoing relationships and gave a sense that teachers could provide leadership to teacher candidates new to the profession and could become genuine educational partners in the L2P teacher education project, thus expanding and extending the PLN to include other members.

\section{Seeking Opportunities and Creating Experiences}

In a sustainable leadership model, leaders shift from problem solving to problem finding and to actively seeking opportunities. This PLN project leadership team continually sought out opportunities to provide support to teacher candidates, and early career and senior teachers, and to address an ongoing problem-lack of connection between school and university for professional educational learning. Building on previous district initiatives to support mentorship, inquiry, and professional learning, the district leaders saw opportunities to work more closely with the teacher education program. Once the L2P project was conceptualized, the teacher education team worked to enable university instructors to understand and integrate school-based learning into their own courses and the district team developed the structure for ongoing professional learning workshops that involved both teachers and teacher candidates. District funding was utilized to support teacher release time and lunches with all the teacher candidates. As noted by Campbell's (2017) review, both time and opportunity to connect are critical elements in supporting teacher professional learning. Enabling such a connecting space, beginning each time with good food and the formation of groups mixed with teachers, teacher educators, and teacher candidates, enabled the continuation of professional learning through preservice to in-service.

The partnership, once developed, provided opportunities for ongoing development of learning and leading for all participants - partnering educators, teacher candidates, and partnership leaders from both institutions. As relationships developed, all participants came to recognize the expertise of the others and the opportunities for shared leadership grew. In subsequent L2P professional learning workshops, teachers became leaders, guiding the teacher candidates to new insights and deeper understandings. The structure of the workshops also enabled teacher candidates, themselves with expertise, to begin leading conversations with their table groups. The partner educators engaged in meaningful and complex conversations with both teacher candidates and their colleagues, enabling a growing recognition of their own practices and beliefs as well as increased articulation of their purpose and expectations. This mixing and clustering of people, committed to being worthwhile educators, created a sense of professional coherence; as Wheatley (2010) notes, "If people are free to make their own decisions, guided by a clear organizational identity for them to reference, the whole system develops greater coherence and strength. The organization is less controlling, but more orderly" (Chapter 5, para. 35). And in such a system we learn "how to grow and evolve in the midst of constant flux" (Gallagher \& Thordarson, 2018). 
Engaging in professional conversations early in their careers offered insights for the teacher candidates about ways in which teachers think, lead, and develop their practices. In a complexity thinking iterative process, teacher candidates were able to engage in professional practices, observe teachers in their classroom contexts, reflect on their evolving assumptions about teaching and inquire into ideas as they returned to further professional discussions, as noted in the anecdote below:

In October 2017, as L2P began its second year, we saw evidence of this partnership beyond what we had originally imagined. One of the teacher candidates had undertaken an inquiry project on ELL learners. She subsequently collaborated with the district ELL Coordinator and created a display entitled Building Community. It was on display at the School Board Office through May and June and is now on display at a local middle school, where the teacher candidate was part of a lunchtime group supporting students new to Canada. Our teacher candidates were engaged in professional learning and sharing their knowledge in authentic ways with a real audience.

The regular half-day meetings/workshops hosted by the district leaders served to create a shared vision, one that participant teachers and teacher candidates owned as well as the project leaders. Ongoing sharing of the purposes for the experiences, such as connecting to curriculum transformation, supporting innovations, personalizing learning for all students, fostered collective ownership and decision-making. Regular input was elicited and the feedback provided direction for future gatherings. Not only did the teacher and teacher candidate feedback provide direction, but it also shaped the ongoing experiences. The PLN became good at receiving feedback in order to continually develop the L2P project. All participants were encouraged to ask questions, think creatively and critically to meet the project goal-ultimately to provide meaningful experiences for all participants that would enhance our shared understanding and efficacy as educators. The experiences created by district leaders pushed at the edges of participants' comfort and challenged them to grow. The teachers were asked to share their approaches to inquiry, and to develop projects aimed at developing student autonomy, with their colleagues and with teacher candidates who were not yet comfortable with release of responsibility to their students. Teachers also shared their new thinking about assessment approaches that aligned with inquiry and project-based pedagogies - fairly new and risky areas for them as well as the teacher candidates.

Attending these workshops and participating together, the research team was able to see and feel shared and sustainable leadership developing. Teachers were animatedly taking opportunities to share their work and their thinking with peers and teacher candidates, bringing samples of their work, leading the learning conversations. As the term progressed, it became increasingly difficult to identify the teachers from the teacher candidates as all were engaged in sharing views, ideas, and questions - all learning to lead discussions, taking responsibility for their own and each other's learning. The workshops became meaningful experiences for everyone. Through teachers' articulation of their work, teacher candidates sharing and connect their ideas to the teachers' work, they came to value each other's contributions, and grow as individuals and as a community of learners/leaders.

\section{Challenging Rules}

What stands in the way becomes the way (Brown, 2018, p. 6). 
Sustainable leadership requires that we do not accept the status quo, but always imagine something better as we embrace the need to change - for our students and ourselves, thoughtfully challenging the way things are 'always' done. Rather than dictating next directions, we need to become accepting of the complexity/messiness of (professional) learning in an ongoing and nourishing way (Hoban, 2002). We learn not to shy away from critical questions and suggestions, but to reflect on these, consult with each other, and arrive at new ways - ways that might question existing rules and norms. Leaders in today's complex world need to rely on each other, to support making "good" mistakes and learn from attempts. As the L2P practice developed, the BC curriculum went through a seismic redesign, shifting from prescribed learning outcomes and provincial exams to competency-based assessment and personalized curriculum development. Though the new curriculum design was well supported by current educational thought on assessment and curriculum development for the 21st century ( $\mathrm{Fu}$ et al., 2018), transition to the new curriculum had been resisted by some teachers, especially as minimal support for change redesigned curriculum had been given.

However, within the L2P project, changes that embraced the redesigned curriculum were already happening. Rather than waiting to be led or given "permission" to try something new, teachers and teacher candidates in the L2P project learned that innovation and new approaches are the norm and that rules/guidelines need to be questioned and sometimes replaced as we move forward, as the educational system adapts to the needs of emerging society. These critical questions and reflections were identified in their inquiry projects, ongoing discussions, and their developing confidence as noted in their conversation interactions. By supporting teachers and teacher candidates to challenges existing norms and rules, the L2P project interactions were implicitly giving permission for them to experiment and become more explicit about what outdated practices they could leave behind. Sharing resources and discussing the meaning of the theoretical underpinnings of documents such as the Ministry's BC's Redesigned Curriculum (2017), support was offered for understanding, challenging and changing teachers' and teacher candidates' beliefs about their practices and assumption about schools.

In support of this process, Wheatley (2010) notes that,

Any mature ecosystem....achieves stability by supporting change within itself. Small, local disturbances are not suppressed; there is no central command function that stamps out these local fluctuations. It is by supporting them that the global system preserves its overall stability and integrity. (Chapter 5, para. 36)

The L2P practices connected to and brought to life, for the teacher candidates, the intents of the $\mathrm{BC}$ redesigned curriculum as they saw the practicing teachers question past practices and embrace new ones in response to the new curriculum.

\section{Developing and Sustaining the Team Through Shifting Roles}

Team-builders get things done and create rapid learning cycles for their teams (Gallagher \& Thordarson, 2018). As leaders in this project, the researchers had insights about teacher and teacher candidate participants, which enabled the L2P team to recognize and nurture their educative and leadership strengths, utilizing these to shape the conversations and activities. The leadership team realized as they worked together the diverse talents and creativities within the group as they began to recognize it and then draw on it. They recognized that "who we are is how we lead" (Brown, 2018, p. 164) and early meetings enabled the team to explore their own 
professional identities, values and beliefs. Once the team became established, with the addition of teachers volunteering to participate in the project, the leadership team realized that they needed to guide from the edges, turning over leadership opportunities to others, whether it was at the schools during Wednesday visits or during the three annual professional workshops.

Through the opportunities created by the L2P project, others began to take up the leadership roles, contributing, suggesting, and creating new approaches. These experiences supported teachers and teacher candidates to become leaders and decision-makers in their own right as the established and re-established networks of learning and growth. As Wheatley (2010) notes, in quantum physics "parts do not remain as parts; they are drawn together by processes of internal connectedness," similarly "we have all experienced things 'coming together,' or been in team efforts that far exceed what we could do alone" (Chapter 6, para. 53). It is this sense of "internal connectedness" where the teachers and teacher candidates feel part of a whole that they lead and are led by, that develops a sense of sustainable leadership.

Throughout the workshops, the leadership team continually circulated, taking part in conversations, offering suggestions, providing resources and materials for further thinking and acting. Facilitation of leadership development became critical to the leadership team as they gradually learned to release responsibility for the workshops and encourage teachers to step upexpecting sharing of their best selves to ultimately work for their students. The district leaders recognized the conditions needed to foster growth, understanding that teachers are often very busy, connected to the ongoing nature of their teaching lives, and are tired. Giving them space and time (an afternoon of professional learning), as well as nourishment (good lunch, encouragement) was of importance in supporting their development as leaders. Telling the story is also a role of sustainable leaders, as the leadership team shifted perspectives - sharing in the lived day-to-day experiences and concerns of teachers and teacher candidates, and also sharing more distanced perspectives offered through educational theory and practice documents from resources both locally and internationally.

\section{Telling the Good Story-Becoming a Storyteller}

The shared stories told by all participants in L2P, using multiple storytelling devices (conversation, short videos, inquiry project presentations, table discussions), highlighted how the work of multiple people could be distributed to multiple audiences in many different waysallowing an array of diverse voices to get heard and valued. Stories make connections. For example, one of the leadership team chose to create a video with a teacher candidate about her experiences, both successes and challenges with an inquiry project in a primary classroom-a video that was shared at subsequent workshop meetings. In this way, not only the participants in the room but others who had participated previously had their voices heard and respected.

Gallagher \& Thordarson (2018) note, "Stories capture hearts and minds of a community to amplify and continue developing authentic community" (p. 135). Storytelling is a powerful way to convey ideas and challenges; sharing stories of learning, of tensions, and conflicts helps to communicate in difficult conditions. Using a "dwelling mind" (Wheatley, 2017) to reflect on our experiences and stories enables us to take time, reflect deeply, and act wisely. In telling the stories, the research team came to better recognize and articulate their shared values, and in so doing recognize ways in which those values were not just named but also practiced. All good stories need tensions and conflicts, which is what makes a story worth living and telling. Sharing stories 
enabled the research team to support each other and encourages others to try new ways of working and learning together. Complex learning systems, as noted by Cilliers (2000), "have memory, not located at a specific place, but distributed throughout the system" (p. 24) embedded in its very structure. Wheatley (2010) notes "in order to change, the system needs to learn more about itself from itself. The system needs process to bring it together" (Chapter 8).

\section{Summary of Findings}

Below is a summary, in relation to our research questions, of the key elements identified in our previous analysis of the L2P story from the perspective of distributed feminist leadership framed by complexity thinking. In response to the first question, "How can educational leaders in school districts and teacher education programs design spaces that engage everyone, recognize everyone's expertise and share responsibility for growth and development?" we have identified in Table 1 the following key learnings related to common attractors and interconnections in forming a complex learning system.

\section{Summary Points of Key Ideas for How to Set Up L2P Project}

1. Attractor - focus was on creating conditions conducive to initiating Professional Learning Communities and Networks:

- Connected teacher education preservice and in-service for ongoing professional learning,

- Came together through a mutual desire to enhance what was already working well but could become better, and

- Recognized and articulated a common desire to restructure roles and building a new relationship between TEP and school district.

2. Neighbourly interactions - set up and interconnected across professional communities:

- School teachers, as partnering educators/leaders, committed to modeling effective teacher practices, engaged in peer-coaching conversations, provided opportunities for teacher candidates to work with groups of students and develop leadership capacity;

- School district leaders as university-connected seminar instructors of the teacher candidates, connected practice to theory in meaningful and in situ ways in local schools as sites of learning every week; and

- Combined district professional learning afternoons on teacher-led inquiry projects with TC seminar classes, reinforcing teacher inquiry as professional learning.

3. Redundancy-The L2P leadership team developed empathy for the others in diverse contexts as:

- Members related first to each other and then to the teachers and teacher candidates they were supporting-creating mutually supportive empathic environment for intuitive respectful connections, and

- Teachers became more genuine educational partners with teacher candidates, with empathetic perspectives becoming the self-similarity of walking the talk that transfers to the teacher candidates.

4. Recursive elaboration - The L2P team sought new opportunities and created meaningful experiences as they:

- Shifted from problem solving to problem finding, all members of the PLN actively sought opportunities to learn by addressing these problems, 
- Worked to enable university instructors to understand and integrate school-based learning into their own courses and the district team developed the conditions and structure for ongoing professional learning workshops that involved both teachers and teacher candidates,

- Developed positive relationships where all participants recognized the expertise of the others, thus enabling opportunities for shared leadership to grow,

- Engaged in professional conversations early in TCs careers offered them insights about ways in which teachers think, lead, and develop their practices, and

- Connected teachers and teacher candidates in combined meaningful professional as all were engaged in sharing views, ideas, and questions - all learning to lead discussions, their own and each other's learning.

In relation to the second research question of how in teacher education we can begin to move away from the hierarchical, industrialized model of management to one where everyone feels engaged, valued, and heard, we summarize in the following key insights related to adaptive emergence in forming a complex learning system.

\section{Summary of Key Insights for Shifting Leadership Toward More Distributed and Feminist Processes}

1. Ambiguously bounded - the need to question and challenge rules rather than wait to be led:

- Teachers and teacher candidates in the L2P project learned that innovation and new approaches have become the norm and that rules/guidelines need to be questioned and sometimes replaced as education and educators move forward, and

- L2P project interactions were implicitly giving permission for teacher candidates to experiment and become more explicit about outdated practices they could leave behind.

2. Decentralized control-The L2P team realized the importance of developing and sustaining the team through shifting roles through:

- Realizing the need to guide from the edges, turning over leadership opportunities to others both at the school sites during Wednesday visits and during the three annual professional workshops,

- Realizing the importance of supporting teachers and teacher candidates in becoming leaders and decision-makers in their own right as the established and re-established networks of learning and growth developed, and

- Recognizing the importance of giving teachers and TCs space and time (a full afternoon of professional learning), as well as nourishment (good lunch, encouragement) to support their ongoing development as leaders.

3. Collective memory-The L2P team recognized the value of telling good stories and becoming storytellers as leadership skills:

- They valued stories as connectors and using storytelling devices (conversation, short videos, inquiry project presentations, table discussions) to highlight the work of multiple people that can be shared with varied audiences in many different ways where all voices get heard and valued 
- The team knew that all good stories need tensions and conflicts, making the story worth living, remembering and telling to enable the community to support and encourage each other in trying new ways of working and learning together.

The writing of this paper is another way to tell our story, to share the challenges and the opportunities that arise in conversation and connection as we collectively lead our way to new understandings of sustainable leadership, professional learning and responsive education. As noted by Campbell (2017), there is a need for genuine embedded professional development in education; this study captures the essence of this need, using a distributed and sustainable leadership model that tries to live these ideas. And the story continues to develop with one of the author's reflective stories recounted below:

\section{Already Educational Leaders:}

Sitting at this teacher education conference, I have been in sessions focused on developing preservice teacher education. Faculty, instructors and program coordinators lead most sessions. I am listening to three students from the L2P program. One of the students opens the session with a confident and meaningful acknowledgment of the land; he draws on his own experience as an outdoor educator, honouring the First Peoples whose land the University is built upon. The students then share anecdotes from their experiences in the school district PD sessions on inquiry projects in assigned schools, connecting their learning to the teacher education program competencies. The audience is impressed by their insights. One student explains,

All these issues you get in the program, in the books, you talk to your instructors about it, but stepping in to the classroom, seeing how all of these questions can be answered by the relationships built between a teacher and the student, was... it was an amazing experience for me.

Another student with Indigenous background spoke of how her mentor teacher encouraged her to lead the class activity on the orange shirt day. As she said,

He had never attempted to address indigenous education or residential school history, because of my life experiences and passion, he asked me to speak to the class; to guide him. It was really wonderful. And now he has taken what I gave him and shared it with other teachers, sort of that ripple effect.

Both these accounts and other examples spoke to the interconnectedness of the L2P experience. At the end of the session a colleague from another institution could not believe these student teachers had just done their first term. As she commented to me, "They are already educational leaders and they have not even begun a practicum."

\section{Conclusion}

As Sergiovanni (2007) suggests, our understanding of leadership is outdated. He states that leaders do not let their schools or educational institution down; the failure often rests with the systems in which they lead. As Hargreaves and Fink (2004) have noted, "Leadership and improvement are interconnected and stretched over time and space. This is the essence of their sustainability" ( $p$. 251). Sustainable leadership can no longer be left to individual managers or administrators working in hierarchical top-down systems, no matter how effective they are in those roles. 
Leaders, through robust PLNs, can learn to do their work collaboratively in order to sustain lasting support and change. As noted by Shaw (2018), leaders need to connect, reflect, and respect others' perspectives in order to sustain ongoing change that is an increasingly inevitable dimension of complex 21 st century life. Key to sustainable leadership in the L2P project was the forming of the PLN between the leaders so that decision making was informed by and shared with diverse perspectives. In this way "leadership is distributed in an emergent and even an assertive way, so that the community engages in evidence-informed and experience grounded dialogue about the best means to promote the goals of deep and broad student learning for all" (Hargreaves \& Fink, 2004, p. 267).

Feminist views and values, as expressed through distributed leadership models but traditionally excluded from leadership conversations, are continuing to challenge the status quo and are encouraging, demanding, and creating change. As suggested in our L2P project, we can all experience shared leadership roles in collaborative and connected ways. We all need to experience leadership so we know how difficult it is, how much we need to know, and how we need to connect with others. By everyone sharing their experiences, memories, and stories - rather than giving directives or advice-we make room for structural memory and understanding that moves us all forward. However, ultimately it is through relationship, caring, and nurturing, fostered by engaging in PLNs, that we will build new ways of understanding sustainable leadership that benefit our students, teachers, and administrators. Ultimately, we believe this creates a resilient community that is self-sustaining, responsive, and compassionate.

In summary, Wheatley (2010) links us back to insights from complexity theory, noting that people working as part of a complex learning system need to be connected to the fundamental identity of the community. People need to be connected to new information as it informs what they do and believe. And people need to be able to reach past traditional boundaries and develop relationships with people anywhere in the system. The Link-to-Practice project, as an example of a PLN informed by tenets from the new sciences shows that this is indeed possible and is a powerful way to support educators (district leaders, teachers, teacher educators, and teacher candidates) as learners and as leaders throughout their careers.

\section{References}

Batliwala, S. (2013). Engaging with empowerment: An Intellectual and Experimental Journey. New Delhi, India: Women Unlimited.

Bennett, N., Wise, C., Woods, P. A., \& Harvey, J. A. (2003). Distributed leadership: A review of literature distributed leadership. London, UK: National College for School Leadership.

Brown, B. (2018). Dare to lead: Brave work. Tough conversations. Whole hearts. New York, NY: Random House.

Brown, C., \& Poortman, C. (2018). Introduction. Networks for learning: Effective collaboration for teacher, school and system improvement. London, UK: Routledge.

Campbell, C. (2017). Developing teachers' professional learning: Canadian evidence and experiences in a world of educational improvement. Canadian Journal of Education, 40(2), 1-33. 
Capra, F., \& Luigi Luisi, P. (2014). The systems view of life: A unifying vision. New York: Cambridge University Press.

Cilliers, P. (2000). What can we learn from a theory of complexity? Emergence, 2(1), 23-33. Retrieved from http://www.complexityandsociety.com/files/1813/1692/0268/Snares.pdf\#page=24

Clover, D. E., Etmanski, C., \& Reimer, R. (2018). Gendering collaboration: Adult education in feminist leadership. New Directions for Adult and Continuing Education, 2017(156), 2131. https://doi.org/10.1002/ace. 20247

Collyer, V. (2016). L2P. [Flyer]. Victoria, BC: Author.

Creswell, J., \& Miller, D. (2000). Determining validity in qualitative inquiry. Theory Into Practice, 39(3), 124-130. https://doi.org/10.1207/s15430421tip3903

Davis, B., Sumara, D., \& Luce-Kapler, R. (2015). Engaging minds: Cultures of education and practices of teaching. New York, NY: Routledge.

Fairholm, M. R. (2004). A new sciences outline for leadership development. Leadership \& Organization Development Journal, 25(4), 369-383.

https://doi.org/10.1108/01437730410538699

First Peoples Principles. (n.d.). Retrieved from https://www.google.com/search?client=firefox$\underline{b-d \& q=F i r s t+P e o p l e s+P r i n c i p l e s}$

Fu, H., Hopper, T. F., \& Sanford, K. (2018). New BC curriculum and communicating student learning in an age of assessment for learning. Alberta Journal of Educational Research, 64(3), 264-286. Retrieved from https://journalhosting.ucalgary.ca/index.php/ajer/article/view/56425/pdf

Fullan, M. (2005). Leadership \& sustainability: System thinkers in action. Thousand Oaks, CA: Corwin Press.

Furman, G. (2012). Social justice leadership as praxis: Developing capacities through preparation programs. Education Administration Quarterly, 48(2), 191-229. doi:10.1177/0013161X11427394

Gallagher, A., \& Thordarson, K. (2018). Design thinking for school leaders: Five roles and mindsets that ignite positive change. Alexandria, VI: ASCD.

Greene, M. (1995). Releasing the imagination: Essay on education, the arts, and social change. San Francisco, CA: Jossey-Bass.

Hargreaves, A., \& Fink, D. (2004). The seven principles of sustainable leadership. Educational Leadership, 61(7), 8-13.

Hopper, T. (2015). Self-study of an elementary generalist PE teacher educator: School integrated teacher education and structural coupling. Asia-Pacific Journal of Health, Sport and Physical Education, 6(3), 259-272. https://doi.org/10.1080/18377122.2015.1092723 
Mason, M. C. (2008). What is complexity theory and what are its implications for educational change? Educational Philosophy and Theory, 40(1), 35-49. Retrieved from http://dx.doi.org/10.1111/j.1469-5812.2007.00413.x

Riessman, C. (2008). Narrative methods for the human sciences. London, UK: Sage Publications.

Sanford, K., Hopper, T., \& Starr, L. (2015). Transforming teacher education thinking: Complexity and relational ways of knowing. Complicity: An International Journal of Complexity and Education, 13(2), 26-48. Retrieved from https://journals.library.ualberta.ca/complicity/index.php/complicity/article/view/23817

Sergiovanni, T. J. (2007). Rethinking leadership: A collection of articles $\left(2^{\text {nd }}\right.$ ed.). Thousand Oaks, CA: Corwin Press.

Smith, B., \& Sparkes, A. C. (2009). Narrative inquiry in sport and exercise psychology: What can it mean, and why might we do it? Psychology of Sport and Exercise, 10(1), 1-11. https://doi.org/10.1016/j.psychsport.2008.01.004

Sparkes, A., \& Smith, B. (2014). Qualitative research methods in sport, exercise and health: From process to product. London, UK: Routledge. https://doi.org/10.4324/9780203852187

Stake, R. (2005). Case studies. In N. K. Denzin \& Y. S. Lincoln (Eds.), The handbook on qualitative research (3rd ed., pp. 443-466). Chicago, IL: Sage.

Uhl-Bien, M., Marion, R., \& McKelvey, B. (2007). Complexity leadership theory: Shifting leadership from the industrial age to the knowledge era. The Leadership Quarterly, 18(4), 298-318. https://doi.org/10.1016/j.leaqua.2007.04.002

Wakefield, S. (2017). Transformative and feminist leadership for women's rights. Oxfam America Research Backgrounder Series.

Waldrop, M. M. (1992). Complexity: The emerging science at the edge of chaos and order. New York, NY: Simon and Schuster.

Wenger, E. (1998). Communities of practice: Learning, meaning, and identity. Cambridge, UK: Cambridge University Press.

Wheatley, M. J. (2010). Leadership and the new science: Discovering order in a chaotic (3rd ed.). San Francisco, CA: Berrett-Koehler Publishers, Inc.

Wheatley, M. J. (2017). Who do we choose to be?: Facing reality, claiming leadership, restoring sanity. New York, NY: Berrett-Koehler.

Wheatley, M., \& Frieze, D. (2015). Lifecycle of emergence: Using emergence to take social innovation to scale. Kosmos Journal for Global Transformation, Summer, 45-50. Retrieved from https://www.kosmosjournal.org/article/lifecycle-of-emergence/ 